|| ISSN(online): 2589-8698 || ISSN(print): 2589-868X || International Journal of Medical and Biomedical Studies Available Online at www.ijmbs.info

PubMed (National Library of Medicine ID: 101738825) Index Copernicus Value 2018: 75.71

\title{
A CLINICO-PATHOLOGICAL STUDY ON HYSTERECTOMY IN A TERTIARY CARE HOSPITAL
}

\author{
Dr. C. Venkata Harish ${ }^{1}$, Dr. B. Bhanumathi ${ }^{2}$, Dr. N. Kathya ${ }^{3}$, Dr. PM. Rekha Rao ${ }^{4}$, Dr. Dumpala \\ Vijayalakshmi $^{5}$, Dr. Shankar Reddy Dudala ${ }^{6}$ \\ ${ }^{1}$ Assistant Professor, Department of Pathology, Government Medical College, Kadapa, AP. \\ ${ }^{2}$ Post Graduate, Department of Anatomy, Government Medical College, Kadapa, AP. \\ ${ }^{3}$ Private Practioner, Gynaecologist, Produttur, AP. \\ ${ }^{4}$ Assistant Professor, Dept of Gynaecology and Obstetrics, Government Medical College, Kadapa, A.P. \\ ${ }^{5}$ Senior Resident, Dept of Gynaecology and Obstetrics, Government Medical College, Kadapa, A.P. \\ ${ }^{6}$ Associate Professor in Community Professor, Government Medical College, Kadapa, A.P.
}

Article Info: Received 20 April 2019; Accepted 6 May. 2019

Cite this article as: Harish, CV., Bhanumathi, B., Kathya, N., Rao, PMR., Vijayalakshmi, D., Dudala, SR (2019). A CLINICOPATHOLOGICAL STUDY ON HYSTERECTOMY IN A TERTIARY CARE HOSPITAL. International Journal of Medical and Biomedical Studies, 3(5):55-61.

DOI: https://doi.org/10.32553/ijmbs.v3i5.241

Corresponding Author: Dr.PM.Rekha Rao, Assistant Professor, Dept of Gynaecology and Obstetrics, Government Medical College, Kadapa, A.P

Conflict of interest: No conflict of interest.

\section{Abstract:}

Background: Uterus is a very vital reproductive organ and is subjected to many benign and malignant diseases. Hysterectomy is one of the most frequently performed procedures all over the world. Aim: Clinico pathological study on hysterectomy in a tertiary care hospital.

Materials and Methods: In this study, 150 cases of hysterectomy were analysed from April 2016 to August 2017 at RIMS, Kadapa.

Results: In histo pathological diagnosis leiomyoma was the most common pathology identified comprising of 43cases (28.6\%). Secretory Phase was seen in 26 cases (17.3\%). Adenomyosis was encountered in 21 cases (14\%).

Keywords: Fibroid uterus, DUB, Hysterectomy, Leiomyoma, Uterine prolapse, Kadapa

\section{Introduction}

Hysterectomy is most common gynaecological operation in India and also in the world1. Charles Clay performed first subtotal hysterectomy in 1843 and first total hysterectomy in 1929 in England. ${ }^{1,2}$ Hysterectomies are done for definitive treatment of multiple pathologies of female reproductive organs like fibroids, uterine prolapsed, abnormal

uterine bleeding, adenomyosis, endometriosis etc of female reproductive organs. ${ }^{3,4}$

Recently, reports have identified hysterectomy as a key health care indicator used to measure and compare hospital performance. ${ }^{5}$ Lately, hysterectomy rates are also decreasing due to better availability of alternative methods. ${ }^{6}$ But in spite of large number of potential alternatives to hysterectomy for benign diseases, hysterectomy rates have remained relatively stable because it is associated with higher rates of patient satisfaction than other methods. ${ }^{7,8}$

Types of Hysterectomies include Abdominal hysterectomy (AH), Vaginal Hysterectomy (VH), Laparoscopic hysterectomy and Robotic hysterectomies. These procedures have undergone important changes recently. Abdominal hysterectomy is carried out in cases of gynaecological disorders like Abnormal Uterine Bleeding (AUB), Fibroids, endometriosis, and in malignancies. Vaginal hysterectomy which is considered to be less invasive than abdominal hysterectomy is usually indicated in gynaecological disorders for prolapsed uterus. But now vast worldwide literature has demonstrated its applicability in other common benign disorders with no uterovaginal descent like uterine leiomyoma, 
adenomyosis, abnormal uterine bleeding - a term referred to as Non Descent Vaginal Hysterectomy in non-prolapsed uterus: no scar hysterectomy. ${ }^{9}$

There are very few studies performed where a correlation between histopathological examination of the uterus and the clinical profile of the patient undergoing hysterectomy has been attempted. The present study is undertaken to study trends in hysterectomy in a tertiary care hospital based on the indications of hysterectomy.

\section{MATERIALS AND METHODS}

Complete examination, history, indication, type of hysterectomy, per operative findings, per operative complications, post-operative events is taken from all the eligible patients.

Regarding her obstetric history, age of marriage, duration, mode of delivery so as to know whether they were conducted at home or hospital, conducted by trained or untrained dais, duration of second stage labour, post-natal period events, history of sterilisation, duration since last delivery were noted.

Menstrual history details like age of menarche, regularity of cycles, history of passage of clots and number of pads per day to roughly assess excessive flow, last menstrual periods details were observed.

Detailed general and systemic examination were noted. On abdominal examination any palpable mass, organomegaly, tenderness, ascites, position of umbilicus, any engorged veins and hernial sites were noted.

Local examination of external genitalia, tests for incontinence, per speculum examination findings, status of vagina and cervix, descent of uterus and any discharge per vagina, position and mobility of uterus, forniceal status and recto vaginal examination were analysed in detail.

After the clinical diagnosis, pap smear, dilatation and curettage reports and the following investigations were studied in detail. Details of any medical pre anaesthetic check-up, preparation of patient for hysterectomy, preoperative antibiotics, operative notes showing the date of operation, indication, type of hysterectomy, per operative findings, per operative complications, post-operative events and histopathological reports, advice at discharge, follow up at OPD level were analysed.

Inclusion criteria: All cases who underwent hysterectomy in RIMS, Kadapa during the study period.

Exclusion criteria: 1.Those who do not give consent. 2. Caeserian Hysterectomy.

Case sheets of 150 women who have undergone Abdominal, vaginal or laparoscopic hysterectomy were analysed in detail for the following information.

Sample size: In this study, 150 cases of hysterectomy were analysed from April 2016 to August 2017 at RIMS, Kadapa. All cases which met the inclusion and exclusion criteria were selected for the study.

Institutional ethical clearance was taken for the study.

\section{RESULTS:}

150 cases of hysterectomy were analysed from April 2016 to August 2017 at RIMS, Kadapa.

Table 1: Clinical Diagnosis

\begin{tabular}{|l|l|l|l|}
\hline S. No. & Clinical Diagnosis & No. & Percentage \\
\hline 1. & Fibroid uterus & 46 & $31 \%$ \\
\hline 2. & Prolapse & 44 & $29.3 \%$ \\
\hline 3. & Adenomyosis & 15 & $10 \%$ \\
\hline 4. & Endometrial causes & 15 & $10 \%$ \\
\hline 5. & Endometrial polyp & 4 & $2.6 \%$ \\
\hline 6. & DUB & 11 & $7.3 \%$ \\
\hline 7. & PID & 7 & $4.6 \%$ \\
\hline 8. & CIN & 1 & $0.6 \%$ \\
\hline 9. & Ovarian cyst & 4 & $2.6 \%$ \\
\hline 10. & Postmenopausal bleeding & 3 & $2 \%$ \\
\hline & Total & 150 & \\
\hline
\end{tabular}


Regarding the indications for hysterectomies, separate observations were made for abdominal, vaginal and laparoscopic approach. It is noted that maximum number of vaginal hysterectomies were done for prolapse uterus, maximum number of abdominal hysterectomies were done for fibroid uterus, laparoscopic approach was for fibroid uterus and DUB.

Table 2: Histopathology of Uterus

\begin{tabular}{|l|l|l|l|}
\hline S.NO & HISTOPATHOLOGY & NO. & PERCENTAGE \\
\hline 1. & Leiomyoma & 43 & $28.6 \%$ \\
\hline 2. & Adenomyosis & 21 & $14 \%$ \\
\hline 3. & Endometrial Hyperplasia & 9 & $6 \%$ \\
\hline 4. & Cystic Glandular Hyperplasia & 11 & $7.3 \%$ \\
\hline 5. & Secretory Phase & 26 & $17.3 \%$ \\
\hline 6. & Proliferative Phase & 5 & $3.3 \%$ \\
\hline 7. & Atrophic Endometrium & 5 & $3.3 \%$ \\
\hline 8. & Endometrial Polyp & 2 & $0.13 \%$ \\
\hline 9. & Leiomyosarcoma & 1 & $0.7 \%$ \\
\hline 10. & Nil Particular & 27 & $18 \%$ \\
\hline
\end{tabular}

In histo pathological diagnosis leiomyoma was the most common pathology identified comprising of 43 cases (28.6\%). Secretory Phase was seen in 26 cases (17.3\%). Adenomyosis was encountered in 21 cases (14\%).

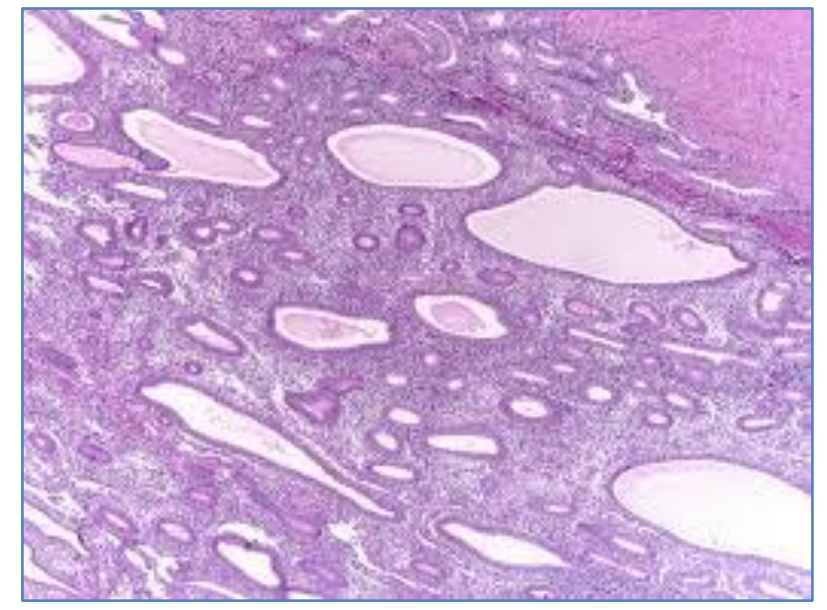

Figure 1: Simple Endometrial Hyperplasia without Atypia

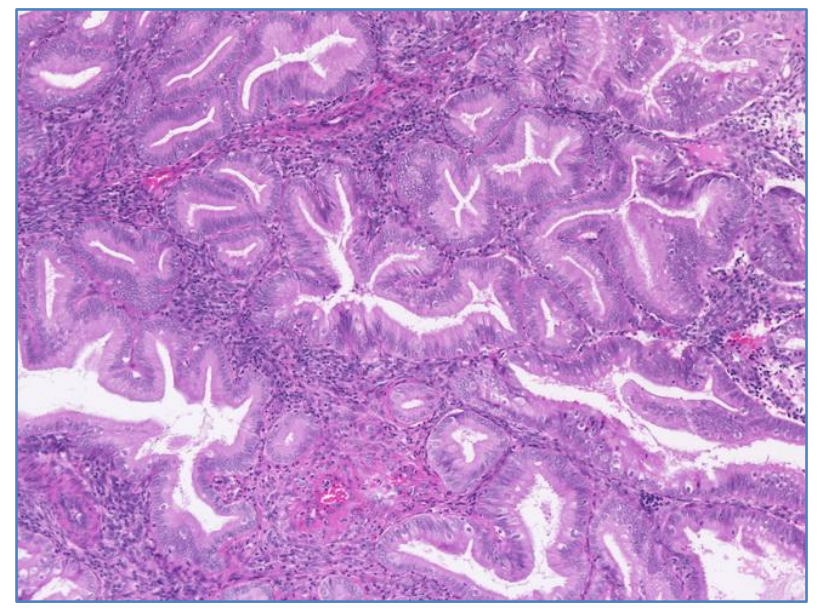

Figure 2: Complex Hyperplasia without Atypia

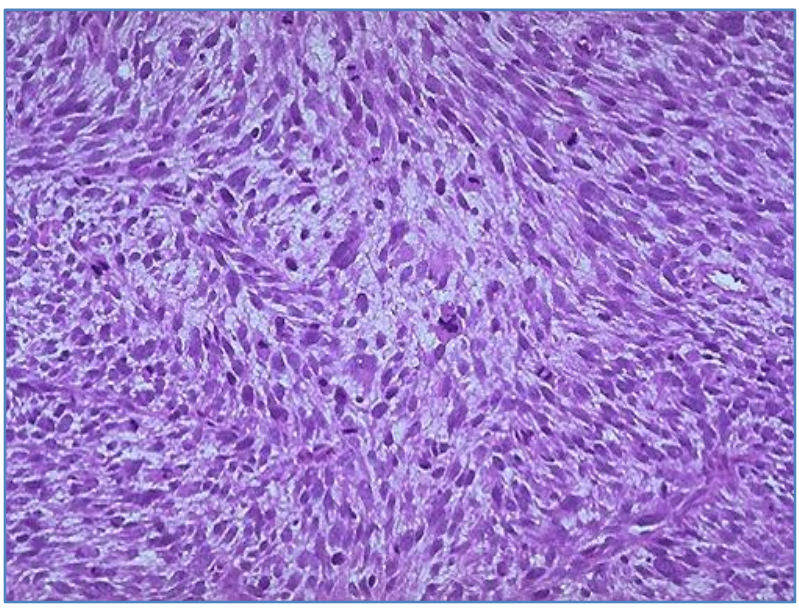

Figure 3: Histopathology- Leiomyosarcoma 
Dr. C. Venkata Harish et al, International Journal of Medical and Biomedical Studies (IJMBS)

Table 2: Histopathology of Cervix

\begin{tabular}{|l|l|l|l|}
\hline S.NO & HISTOPATHOLOGY & No. & Percentage \\
\hline 1. & Nonspecific cervicitis & 100 & $66 \%$ \\
\hline 2. & Koilocytosis & 6 & $4 \%$ \\
\hline 3. & Fibroid polyp & 2 & $1.3 \%$ \\
\hline 4 & Endocervical polyp & 5 & $3.3 \%$ \\
\hline 5. & Endocervical polyp with cervicitis & 3 & $2 \%$ \\
\hline 6. & Adenocarcinoma of cervix & 1 & $0.6 \%$ \\
\hline 7. & Nil particular & 33 & $22.6 \%$ \\
\hline & Total & 150 & \\
\hline
\end{tabular}

Cervicitis was observed in 100 (66\%) cases, fibroid polyp in 2 (1.3\%) cases and unremarkable changes in 33 $(22.6 \%)$ cases.

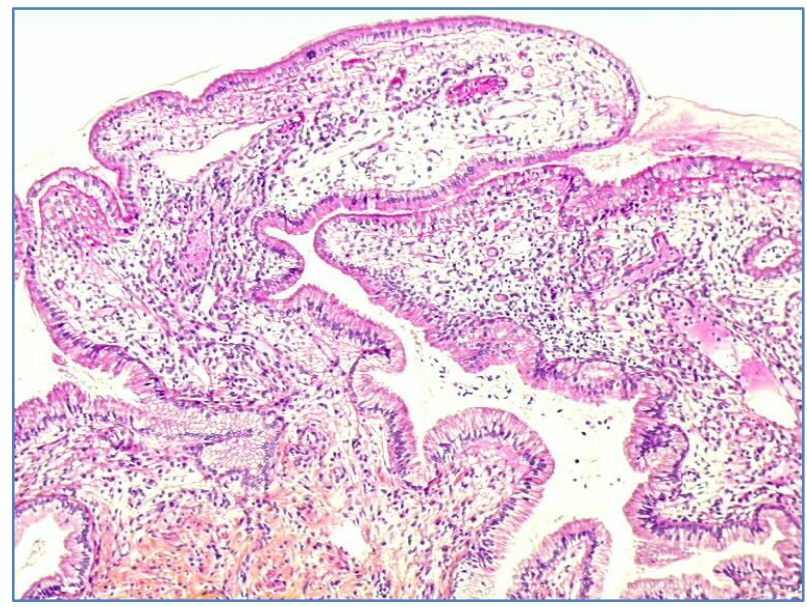

Figure 4: Chronic Cervicitis

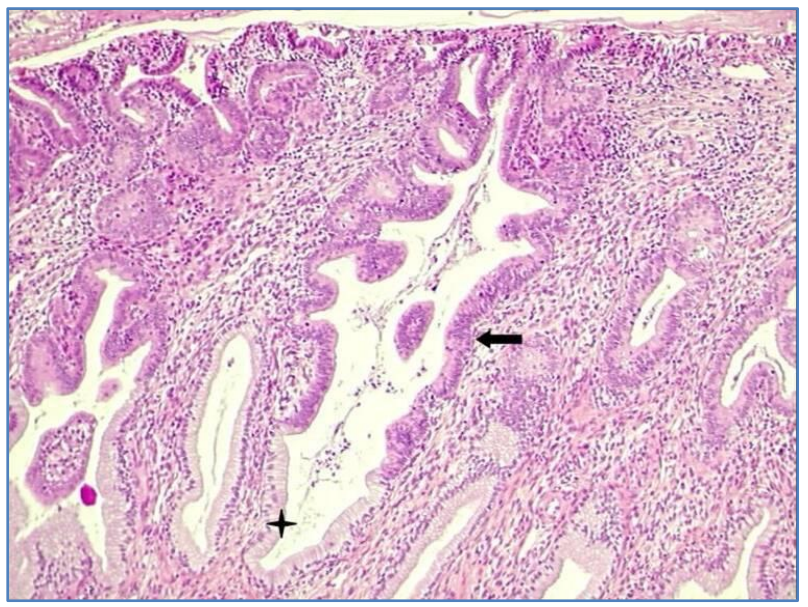

Figure 5: Adenocarcinoma of Cervix

Table 3: Histopathology of Ovaries

\begin{tabular}{|l|l|l|l|}
\hline S.No & HISTOPATHOLOGY & NO. & PERCENTAGE \\
\hline 1. & Corpus albicans & 28 & $37.3 \%$ \\
\hline 2. & Functional cysts & 5 & $6.6 \%$ \\
\hline 3. & Cortical cysts & 1 & $1.3 \%$ \\
\hline 4. & Serous cystadenoma & 1 & $1.3 \%$ \\
\hline 5. & Nil particular & 40 & $53.3 \%$ \\
\hline & TOTAL & 75 & \\
\hline
\end{tabular}

75 cases had ovaries removed. 40(53.3\%) cases had no pathology which constituted the maximum amount. 
Table 4: Comparison of Various Indications with Surgical approach

\begin{tabular}{|l|l|l|l|l|}
\hline S.no & Diagnosis & $\begin{array}{l}\text { Abdominal } \\
\text { hysterectomy }(n=55)\end{array}$ & NDVH(n=10) & $\begin{array}{l}\text { Laparoscopic } \\
\text { hysterectomy }(n=41)\end{array}$ \\
\hline 1 & Fibroid uterus & $30(54.5 \%)$ & $5(50 \%)$ & $11(26.82 \%)$ \\
\hline 2 & DUB & $1(1.8 \%)$ & $2(20 \%)$ & $8(19.51 \%)$ \\
\hline 3 & PID & $1(1.8 \%)$ & - & $6(14.6 \%)$ \\
\hline 4 & Adenomyosis & $8(14.5 \%)$ & $1(10 \%)$ & $6(14.6 \%)$ \\
\hline 5 & Endometrial causes & $4(7.27 \%)$ & $2(20 \%)$ & $9(21.9 \%)$ \\
\hline 6 & Polyp & $3(5.45 \%)$ & - & $1(2.43 \%)$ \\
\hline & $\begin{array}{l}\text { Post menopausal } \\
\text { bleeding }\end{array}$ & $3(5.45 \%)$ & - & - \\
\hline 7 & Ovarian cyst & $3(5.45 \%)$ & - & - \\
\hline 8. & CIN & $1(1.8 \%)$ & - & - \\
\hline 9. & Prolapse & - & $44(\mathrm{VH}+\mathrm{PFR})$ & - \\
\hline
\end{tabular}

Fibroid uterus (54.5\%) is the most common indication for hysterectomy in abdominal hysterectomy patients. Fibroid uterus (50\%) is the most common indication for hysterectomy NDVH patients. Fibroid uterus $(26.8 \%)$ is the most common indication for hysterectomy in laproscopic hysterectomy patients.

\section{DISCUSSION}

This study was a prospective study conducted at Rajiv Gandhi Institute of Medical Sciences and research, Kadapa, YSR District. 150 cases of hysterectomy specimens were subjected to histopathology. Fibroid uterus in the myometrium, chronic cervicitis in the cervix and functional cysts in the ovaries were the commonest histopathology noted. Adenomyosis was the most missed pathology preoperatively.

Only few studies have compared pre-operative clinical diagnosis with the histopathology of hysterectomy specimens. We have found that majority of pre-operative diagnosis of our cases were confirmed on histopathology.

Lee found that out of 1283 women studied, $80 \%$ of the pre-operative diagnosis were confirmed in the potentially confirmable group. 10 Miller studied 246 hysterectomy specimens and found that clinical diagnosis were confirmed in $50 \%$ cases. ${ }^{11}$

In the present study, Leiomyoma $43(28.6 \%)$ was noticed to be the most common histopathological finding and most common indication for hysterectomy. 46 cases were diagnosed as fibroid uterus preoperatively out of which only 43 cases showed leiomyoma on histopathological examination, the other cases, one case had Adenomyosis, one case of cystic glandular hyperplasia and one case of endometriosis each.

Results of the study were similar and in comparison, with other studies.

Archana Bhosle et al in 2010 did a retrospective study of 112 perimenopausal women with abnormal uterine bleeding for a 6 months period. ${ }^{12}$ Fibroid uterus, DUB, and adenomyosis were the principal causes of abnormal uterine bleeding in this study.

Perveen and Tayyab 2008 reviewed 54 elective abdominal hysterectomies and revealed that leiomyoma is the commonest (59. 2\%) pathological lesion. ${ }^{13}$

Yogesh neena et al, in 2013 reported that the final histopathology of hysterectomy specimens exhibited leiomyoma as the most common lesion in $24.6 \%$ cases, adenomyosis in $12.15 \%$ cases, endometrial hyperplasia in $9 \%$ cases, fibroid combined with adenomyosis in $4.8 \%$ and malignancy in $0.34 \%$ cases. $^{14}$

Nisha mohammed et al in 2014, in their study reported leiomyoma (43.7\%) as the common histopathological finding followed by adenomyosis (9.1\%). ${ }^{15}$ 
Table 5: Comparison of various histopathology with present study

\begin{tabular}{|c|l|l|}
\hline Sr. No. & Study design & Percentage \\
\hline 1 & Perveen and Tayyab $^{13}$ & $59.2 \%$ \\
\hline 2 & Archana bhonsele et al $^{12}$ & $54 \%$ \\
\hline 3 & Yogesh neena et al $^{14}$ & $24.6 \%$ \\
\hline 4 & Nisha mohammed et al $^{15}$ & $43.7 \%$ \\
\hline 5 & Present study & $\mathbf{2 8 . 6 \%}$ \\
\hline
\end{tabular}

Histopathology of 21 specimens showed adenomyosis out of which only $15(71 \%)$ cases were diagnosed preoperatively which indicates that adenomyosis is the most common diagnosis that is missed preoperatively. One case of leiomyosarcoma was detected on histopathology which was undiagnosed preoperatively. Non specific cervicitis(66\%) is the most common histopathological finding of cervix in the present study which were similar to studies by Nisha mohammed et al, ${ }^{15}$ Yogesh neena et al. ${ }^{14}$

Adenocarcinoma of ectocervix was diagnosed in one case on histopathology which was unnoticed preoperatively. 75 cases had ovaries removed, 41 cases had no significant pathology noticed, corpus albicans was noticed in $37.3 \%$, functional cysts in $6.6 \%$ cases and one (1.3\%) had serous cystadenoma on histopathological examination.

\section{Conclusion:}

In histo pathological diagnosis leiomyoma was the most common pathology identified comprising of 43 cases $(28.6 \%)$. Secretory Phase was seen in 26 cases $(17.3 \%)$. Adenomyosis was encountered in 21 cases (14\%).

\section{Acknowledgements:}

We would like to thank all the authors from where we have cited for publication of this article.

\section{References:}

1. Ranabhat SK, Shrestha R, Tiwari M, Sinha DP, Subedee LR. A retrospective histopathological study of hysterectomy with or without salpingoophorectomy specimens. www.cmc.edu.np. 24-29.

2. G. Gupta, D.S. Kotasthane, V.D. Kotasthane: Hysterectomy: A Clinico pathological correlation of 500 Cases. The Internet Jour of Gyneco and Obst 2010;14(1). DOI: 10.5580/141b.

3. Nausheen $F$, Iqbal J, Bhatti $F$ A et al. Hysterectomy: The patient's perspective. Annals Gynecol 2004;10:339-41.

4. A retrospective clinico pathological study of hysterectomy cases in a tertiary care hospital in India - a review of 950 cases. Bangladesh Journal of Medical Science Vol. 17 No. 01 January'18.

5. Toma A, Hopman WM, Gorwill RH. Hysterectomy at a Canadian tertiary care facility: results of a one year retrospective review. BMC Women Health. 2004; 4(1):10.

6. Das N, Kay VJ, Mahmood TA. Current knowledge of risks and benefits of prophylactic oophorectomy at hysterectomy for benign disease in United Kingdom and Republic of Ireland. Eur J obstet Gynecol Reprod Biol. 2003;109:76.

7. Dwyer N, Hutton J, Storrat GM. Randomised controlled trial comparing endometrial resection with abdominal hysterectomy for surgical treatment of menorrhagia. Br J Obstet Gynaecol. 1993;100:237-43

8. Fateh puriya DS, Verma L, Sharma S. Clinico pathological study of hysterectomy in benign lesions: a study of 379 hysterectomies. Int J Reprod Contracept Obstet Gynecol 2017;6:9348.

9. PM.Rekha Rao, Dumpala Vijayalakshmi, D.Shankar Reddy. To Study The Trends in Hysterectomy in A Tertiary Care Hospital Based On The Indications of Hysterectomy. IOSR Journal of Dental and Medical Sciences (IOSRJDMS), vol. 18, no.04, 2019, pp 49-53.

10. Lee NC, Dicker RC, Rubin G, Oray HW. Confirmation of the pre-operative diagnosis for hysterectomy. Am J Obstet Gynecol 1984;150(3):283-287.17. 
Dr. C. Venkata Harish et al, International Journal of Medical and Biomedical Studies (IJMBS)

11. Miller NF. Hysterectomy: therapeutic necessity or surgical racket? Am J Obstet Gynecol 1946;51:804.

12. Archana Bhosle, Michelle Fonseca; Evaluation and Histopathological Correlation of Abnormal Uterine Bleeding in Perimenopausal Women; Bombay Hospital Journal, Vol. 52, No. 1, 2010.

13. Perveen S, Tayyab S. Clinico pathological review of elective abdominal hysterectomies. J Sur Pak2008;13:26-9.

14. Yogesh Neena, Bhaskar Honey, "Clinicopathological correlation of hysterectomy specimens for abnormal uterine bleeding in rural area". Journal of Evolution of Medical and Dental Sciences 2013; Vol2, Issue 39, September 30; Page: 7506-7512.

15. Nisha mohammed and Prejisha. A correlation of etiological and histological findings in femalesundergoing hysterectomy for Abnormal Uterine bleeding -in accordance with PALMCOEIN classification. Paripex - Indian Journal of Research 2014;3(11):76-7. 